\title{
L-carnitine ameliorates the liver inflammatory response by regulating carnitine palmitoyltransferase I-dependent PPAR $\gamma$ signaling
}

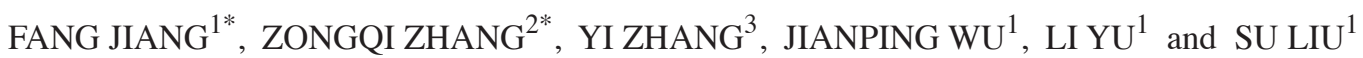 \\ ${ }^{1}$ Department of Gastroenterology, Zhabei District Central Hospital, Shanghai 200070; ${ }^{2}$ Department of Cardiology, \\ No. 3 People's Hospital Affiliated to Shanghai Jiao Tong University School of Medicine, Shanghai 201900; \\ ${ }^{3}$ Department of Gastroenterology, Changzheng Hospital, Second Military Medical University, \\ Shanghai 200003, P.R. China
}

Received January 19, 2015; Accepted October 28, 2015

DOI: $10.3892 / \mathrm{mmr} .2015 .4639$

\begin{abstract}
The liver is crucial for systemic inflammation in cancer cachexia. Previous studies have shown that L-carnitine, as the key regulator of lipid metabolism, exerts an anti-inflammatory effect in several diseases, and ameliorates the symptoms of cachexia by regulating the expression and activity of carnitine palmitoyltransferase (CPT) in the liver. However, the effect of L-carnitine on the liver inflammatory response in cancer cachexia remains to be elucidated. The aim of the present study was to examine the role of the CPT I-dependent peroxisome proliferator-activated receptor (PPAR) $\gamma$ signaling pathway in the ameliorative effect of L-carnitine on the liver inflammatory response. This was investigated in a colon-26 tumor-bearing mouse model with cancer cachexia. Liver sections were immunohistochemically analyzed, and mRNA and protein levels of representative molecules of the CPT-associated PPAR $\gamma$ signaling pathway were assessed using PCR and western blot analysis, respectively. The results showed that oral administration of L-carnitine in these mice improved hepatocyte necrosis, liver cell cord derangement and hydropic or fatty degeneration of the liver cells in the liver tissues, decreased serum levels of malondialdehyde, increased serum levels of superoxide dismutase and
\end{abstract}

Correspondence to: Dr Su Liu, Department of Gastroenterology, Zhabei District Central Hospital, 619 Zhonghua Xin Road, Shanghai 200070, P.R. China

E-mail: liusu2222@163.com

Dr Zongqi Zhang, Department of Cardiology, No. 3 People's Hospital Affiliated to Shanghai Jiao Tong University School of Medicine, 280 Mohe Road, Shanghai 201900, P.R. China

E-mail: zqzhangdoctor@126.com

${ }^{*}$ Contributed equally

Key words: L-carnitine, cachexia, carnitine palmitoyltransferase, peroxisome proliferator-activated receptors, mice glutathione peroxidase, and elevated the expression levels of PPAR $\alpha$ and PPAR $\gamma$ at the mRNA and protein levels. These changes induced by L-carnitine were reversed by treatment with etomoxir, an inhibitor of CPT I. The inhibitory effect of L-carnitine on the increased expression level of nuclear factor (NF)- $\mathrm{B}$ p65 in the peripheral blood mononuclear cells was markedly weakened by GW9662, a selective inhibitor of PPAR- $\gamma$. GW9662 also eliminated the inhibitory effect of L-carnitine on the expression of cyclooxygenase-2 (Cox-2) in the liver, and on the serum expression levels of pro-inflammatory prostaglandin E2, C-reactive protein, tumor necrosis factor- $\alpha$ and interleukin- 6 in the cancer cachexia model mice. This reversing effect of GW9662 on L-carnitine was restored by pyrrolidine dithiocarbamate, a specific inhibitor of $N F-\kappa B$ signaling. Taken together, these results demonstrated that L-carnitine ameliorated liver inflammation and serum pro-inflammatory markers in cancer cachexia through regulating CPT I-dependent PPAR $\gamma$ signaling, including the downstream molecules of NF- $\kappa \mathrm{B}$ p65 and Cox-2.

\section{Introduction}

Cancer cachexia is a common syndrome, characterized by skeletal muscle wasting, with or without loss of fat mass. Systemic inflammation is essential for the pathogenesis of cancer cachexia. C-reactive protein (CRP), a marker of systemic inflammation, has been found to be elevated early in cancer cachexia (1) and is associated with decreased skeletal muscle mass $(2)$. It has been reported $(3,4)$ that the levels of certain pro-inflammatory cytokines, including tumor necrosis factor (TNF)- $\alpha$ and interleukin (IL)-6, are increased in the serum of the mice with cancer cachexia and in patients with cancer cachexia. Other studies $(5,6)$ have demonstrated that TNF- $\alpha$ is directly involved in cachexia by inhibiting lipoprotein lipase and enhancing protein degradation, and that IL-6 promotes skeletal muscle atrophy via signal transducer and activator of transcription-3 (STAT3) signaling.

The liver is crucial for systemic inflammation in cancer cachexia. A previous study (7) demonstrated that the number of IL- 6 and IL-1 immunoreactive cells is significantly 
increased in the locality of CD68-positive areas of the liver in cancer cachexia, and that areas of CD68-positive macrophages in liver biopsies ares increased in the patients with a more aggressive grades of tumor. Further studies have demonstrated that Kupper cells and hepatocytes act as a major source of circulating pro-inflammatory cytokines, including TNF- $\alpha$, IL-6 and proteolysis inducing factor, in cancer cachexia, via the NF- $\kappa \mathrm{B}$ - and STAT3-dependent signaling pathways (8), or the cyclooxygenase-2 (Cox2)/prostaglandin E2 (PGE2) pathway (9). However, there remains controversy regarding the effect of COX-2 on circulating levels of IL-6 (10).

L-carnitine is a key regulator of lipid metabolism and exerts an anti-inflammatory effect in several disease settings. For example, L-carnitine protects against carboplatin-mediated renal injury by inhibiting renal tubular cell apoptosis (11) and, L-carnitine has been demonstrated to prevent the progression of non-alcoholic steatohepatitis in a mouse model by upregulating the mitochondrial $\beta$-oxidation and redox system, accompanied by decreases in the levels of IL- 1 and TNF- $\alpha$ in the liver (12). In addition, L-carnitine has been demonstrated to decrease the protein levels of TNF- $\alpha$ and IL- 6 in the fibrotic liver (13). Notably, the levels of carnitine are markedly decreased in the serum of patients with cancer cachexia (14). Oral supplementation of L-carnitine prevent glutathione from decreasing further in tumor-bearing mice, suggesting that it exerts a beneficial antioxidant effect in cancer cachexia (15). However, the effect of L-carnitine on the liver inflammatory response in cancer cachexia remains to be elucidated.

It is understood that lipid metabolism disorders can induce a pro-inflammatory response in the liver (16). A previous study (17) demonstrated that L-carnitine induces the recovery of liver lipid metabolism dysfunction in cancer cachexia, and is associated with the regulation of the expression levels of carnitine palmitoyltransferase I and II (CPT I and II). Our previous study (3) demonstrated that L-carnitine ameliorates cachectic symptoms by regulating the expression and activity of carnitine palmitoyltransferase (CPT) in the liver, accompanied by a decrease in the elevated serum levels of TNF- $\alpha$ and IL-6, suggesting that CPT is involved in a certain aspect of the liver inflammatory response, regulated by L-carnitine. Additionally, L-carnitine upregulates peroxisome proliferator-activated receptor (PPAR) $\gamma$ (18), a key regulator in the liver inflammatory response and oxidative stress $(19,20)$, which has been found to be involved in regulating the expression of CPT I (21). These findings led the present study to hypothesize that L-carnitine may improve the liver inflammatory response by regulating the CPT I-dependent PPAR $\gamma$ signaling pathway. Therefore, the aim of the present study was to investigate the role of the CPT I-dependent PPAR $\gamma$ signaling pathway in the ameliorative effect of L-carnitine on the liver inflammatory response in cancer cachexia in a colon-26 tumor-bearing mouse model.

\section{Materials and methods}

Animals and cachexia model. The animal experiments performed in the present study were approved by the Institute of Animal Use and Care Committee of Tongji University (Shanghai, China). Adult male BALB/c mice weighing 22-26 g were obtained from the Experimental Animal Center of Tongji
University (Shanghai, China) and housed at $24^{\circ} \mathrm{C}$ with a $12-\mathrm{h}$ light/dark cycle, and free access to water and mouse chow. Cancer cachexia was induced in colon-26 tumor-bearing $\mathrm{BALB} / \mathrm{c}$ mice, as described in a previous study by our group (3). To establish the cachexia model, tumor cells $\left(1 \times 10^{6}\right.$ cells in $0.1 \mathrm{ml}$ of saline) were subcutaneously inoculated into the right axillary fossa of BALB/c mice.

Groups and experimental protocol. Based on the results obtained from our previous study (3), cancer cachexia was considered fully developed 11 days following tumor inoculation. Therefore, subsequent interventions in the present study were initiated on day 12 .

Experiment 1. A total of 18 tumor-bearing mice were equally randomized into a vehicle control group, which received oral administration of $2 \mathrm{ml}$ saline daily; an L-carnitine group, which received oral administration of $9 \mathrm{mg} / \mathrm{kg}$ daily (cat. no. C0158; Sigma-Aldrich, St. Louis, MO, USA); and an L-carnitine+etomoxir group, which received oral administration of $9 \mathrm{mg} / \mathrm{kg}$ L-carnitine daily and intraperitoneal administration of $20 \mathrm{mg} / \mathrm{kg}$ etomoxir, an inhibitor of CPT I (cat. no. E1905; Sigma-Aldrich) daily for 7 days.

Experiment 2. At the same time, a separate group of 30 tumor-bearing mice were equally randomized into a pioglitazone group, GW9662 group, L-carnitine+pioglitazone group, L-carnitine+GW9662 group and L-carnitine+GW9662+ pyrrolidine dithiocarbamate (PDTC) group. The treatment administration was as follows: Pioglitazone hydrochloride, a specific agonist of PPAR $\gamma(10 \mathrm{mg} / \mathrm{kg}$ orally daily; cat. no. E6910; Sigma-Aldrich); GW9662, a selective inhibitor of PPAR $\gamma$ (1 mg/kg daily intaperitoneally; cat. no. M6191; Sigma-Aldrich); L-carnitine $(9 \mathrm{mg} / \mathrm{kg}$ orally $)+$ pioglitazone $(10 \mathrm{mg} / \mathrm{kg}$ per day orally); L-carnitine (9 mg/kg orally) + GW9662 (1 mg/kg per day intraperitoneally); and L-carnitine ( $9 \mathrm{mg} / \mathrm{kg}$, orally) + GW9662 ( $1 \mathrm{mg} / \mathrm{kg}$ per day intraperitoneally) and PDTC $(120 \mathrm{mg} / \mathrm{kg}$ per day intraperitoneally), a selective inhibitor of nuclear factor (NF)-КB, (cat. no. P8765; Sigma-Aldrich;), respectively. In addition, six healthy mice received no treatment, and were used as a normal control group.

Following intervention for 7 days, all mice in each group in experiments 1 and 2 were anesthetized with $2 \%$ intraperitoneal pentobarbital $(40 \mathrm{mg} / \mathrm{kg}$ i.p.; Beyotime Institute of Biotechnology, Haimen, China) and weighed. Blood $(1.5 \mathrm{ml}$ per mouse) was collected from the inferior vena cava, close to the entrance of the hepatic vein. Peripheral blood mononuclear cells (PBMCs) were isolated for the measurement of $\mathrm{NF}-\kappa \mathrm{B}$ p65 using Ficoll-Isopaque Plus density-gradient centrifugation at $800 \mathrm{x} \mathrm{g}$ for $20 \mathrm{~min}$ at $20^{\circ} \mathrm{C}$ (cat. no. 10771; Sigma-Aldrich). The levels of serum inflammatory agents (IL-6, TNF- $\alpha$, PGE2 and CRP) and the oxidative stress markers, malondialdehyde, (MDA) and superoxide dismutase (SOD) and glutathione peroxidase(GSH-Px) were measured. The mice were sacrificed by cervical dislocation. The intact liver was isolated and stored in liquid nitrogen (Sinopharm Chemical Regent Co., Ltd., Shanghai, China).

Measurement of pro-inflammatory markers and oxidative stress markers. The serum levels of TNF- $\alpha$, IL-6, PGE2 and 
CRP were detected using a enzyme linked immunosorbent assay (ELISA) kits (TNF- $\alpha$, cat. no. MTA00B; IL-6, cat. no. M6000B; PGE2, cat. no. KGE004B; CRP, cat. no. MCRP00; R\&D systems, Inc., Minneapolis, MN, USA), according to the manufacturer's protocol. A total of $50 \mu \mathrm{l}$ serum per well was added to a 96-well plate, followed by incubation at $37^{\circ} \mathrm{C}$ for $2 \mathrm{~h}$ and subsequent determination of the color intensity at $450 \mathrm{~nm}$. MDA was measured using a thiobarbituric acid reactive substance assay method, as described previously (22). The reaction products were obtained by isolating the organic layer and read at $532 \mathrm{~nm}$. Serum levels of SOD and GSH-Px were detected using kits (cat. nos. A001-1 and A006-1, respectively; Nanjing Jiancheng Bioengineering Institute, Nanjing, China) according to the manufacturer's protocol. The optical density value was read on a spectrophotometer (F96PRO; Shanghai Lengguang Industrial Co., Ltd, Shanghai, China).

Histologicalanalysis. Thelivertissues were paraffin-embedded, sliced into $5 \mu \mathrm{m}$ sections and stained with hematoxylin and eosin (Beyotime Institute of Biotechnology) for assessment of the degree of liver inflammation, according to previously published criteria (23). The scores $(0-8)$ were used for the assessment of steatosis, lobular inflammation and hepatocyte ballooning. The liver sections were observed under the light microscope equipped with a 10x objective (BM-600B; Ningbo Barride Optics Co., Ltd., Ningbo, China).

Immunohistochemical analysis. The liver sections were incubated with $0.3 \%(\mathrm{v} / \mathrm{v})$ hydrogen peroxide (Beyotime Institute of Biotechnology) for $30 \mathrm{~min}$ at room temperature to quench endogenous peroxidase activity, and were then blocked for $2 \mathrm{~h}$ in phosphate-buffered saline (PBS; Beyotime Institute of Biotechnology) containing 5\% normal goat serum and $2 \%$ bovine serum albumin (Beyotime Institute of Biotechnology). Monoclonal antibodies (diluted 1:200) against PPAR $\gamma$ (Santa Cruz Biotechnology, Inc. Santa Cruz, CA, USA; cat. no. sc-7273) or PPAR $\alpha$ (Abcam, Cambridge, MA; cat. no. ab2779) were incubated with the fixed sections for $2 \mathrm{~h}$, followed by five rinses with PBS. The sections then were incubated with horseradish peroxidase-conjugated goat anti-mouse antibody (diluted 1:500) for $1 \mathrm{~h}$ at room temperature. The relative expression levels of PPAR $\alpha$ and PPAR $\gamma$ were semi-quantitated as integrated optical density/area, as described previously (24).

Reverse-transcription quantitative polymerase chain reaction (RT-qPCR). Total RNA was isolated from the PBMCs using TRIzol reagent (Invitrogen; Thermo Fisher Scientific, Inc., Waltham, MA, USA; cat. no. 15596-018), according to the manufacturer's instructions. The cDNA was generated using a MultiScribe Reverse Transcriptase kit (Applied Biosystems; Thermo Fisher Scientific, Inc.; cat. no. 4368814). RNA (2 $\mu \mathrm{g})$ was reverse-transcribed to cDNA with $1 \mu \mathrm{l}$ oligo(dT) $(0.1 \mu \mathrm{g} / \mu \mathrm{l})$ and $5 \mu 10.1 \%$ diethylpyrocarbonate-treated $\mathrm{H}_{2} \mathrm{O}$ at $70^{\circ} \mathrm{C}$ for $5 \mathrm{~min}$. The primers used were as follows: Forward 5'-ACA GAC CCA GGA GTG ACA A-3' and reverse 5'-CAT GGA CAC ACC CTG GTT CAG-3' for NF- $\mathrm{B}$ p65; and forward 5'-TGG TGG ACC TCA TGG CCT AC-3' and reverse 5'-GCA ACT GAG GGC CTC TCT-3' for GAPDH. All primers were synthesized by Sangon Biotech Co., Ltd (Shanghai, China).
The qPCR reactions were performed using SYBR green PCR master mix (Qiagen, Shanghai, China; cat. no. 204141) in a 50- $\mu 1$ PCR reaction containing $1 \mu 1 \mathrm{cDNA}$ using an iCycler thermocycler (Bio-Rad Laboratories, Inc., Hercules, CA, USA) with the following thermocycling conditions: $50^{\circ} \mathrm{C}$ for $2 \mathrm{~min}$ and $95^{\circ} \mathrm{C}$ for $15 \mathrm{~min}$, followed by 40 cycles of $94^{\circ} \mathrm{C}$ for $15 \mathrm{sec}, 55^{\circ} \mathrm{C}$ for $30 \mathrm{sec}$ and $72^{\circ} \mathrm{C}$ for $30 \mathrm{sec}$. PCR products were detected using an ABI7500 Real-Time PCR Detection system (Applied Biosystems; Thermo Fisher Scientific, Inc.). The house-keeping gene, GAPDH, was used as an internal control. Data were normalized to GAPDH, and the relative expression levels were calculated using the $2^{-\Delta \Delta \mathrm{Cq}}$ method as described previously (3). Experiments were performed in triplicate samples.

Western blot analysis. Total protein extracts were obtained by homogenization of tissues using protein sample buffer [100 mM Tris-HCl (pH 6.8), 200 mM dithiothreitol, 4\% sodium dodecyl sulfate (SDS), $0.2 \%$ bromphenol blue and $20 \%$ glycerol] and a classic protease inhibitor cocktail (Beyotime Institute of Biotechnology). Protein concentrations were measured by the bicinchoninic acid method (Pierce Biotechnology, Inc., Rockford, IL, USA). Protein samples were heated at $100^{\circ} \mathrm{C}$ for $10 \mathrm{~min}$, and $40 \mu \mathrm{g}$ was applied to a 10\% SDS-polyacrylamide gel. Following electrophoresis, the proteins were electrophoretically transferred onto polyvinylidene difluoride membranes (Millipore Co., Billerica, MA, USA). The membranes were stained with $0.5 \%$ Ponceau $\mathrm{S}$ (Beyotime Institute of Biotechnology) to assure equal protein loading, blocked for $1 \mathrm{~h}$ with $5 \%$ powdered non-fat dry milk in $25 \mathrm{mM}$ Tris- $\mathrm{HCl}$ (pH 8.0), $144 \mathrm{mM} \mathrm{NaCl}$ and $0.1 \%$ Tween 20 (TBS-T), and incubated overnight at $4^{\circ} \mathrm{C}$ with the following primary antibodies: PPAR- $\alpha$, PPAR- $\gamma$, NF- $\kappa$ B P65 (cat. no. ab16502; Abcam), Cox-2 (catalog no. sc-166475; Santa Cruz Biotechnology) and $\beta$-actin (cat. no. ab8227; Abcam). Following incubation with the goat anti-rabbit (cat. no. A0277) or mouse (cat. no. A0286) secondary antibodies (Beyotime Institute of Biotechnology; 1:2,000 dilution), the membranes were briefly washed twice and then three times for $10 \mathrm{~min}$ each with TBS-T. Immunodetected proteins were visualized in a FluorChem ${ }^{\circledR}$ HD2 analysis system (Protein Simple Co., Shanghai, China) using the enhanced chemiluminescent ECL assay kit (Santa Cruz Biotechnology, Inc.) according to the manufacturer's recommended protocol.

Statistical analysis. All data are expressed as the mean \pm standard deviation and were analyzed using analysis of variance, followed by a least significant difference t-test for post-hoc comparison. SPSS 13.0 software (SPSS, Inc., Chicago, IL, USA) was used for all statistical analyses. $\mathrm{P} \leq 0.05$ was considered to indicate a statistically significant difference.

\section{Results}

L-carnitine relieves the liver inflammatory response in mice with cancer cachexia. Compared with the normal control mice (Fig. 1A), histological analysis of the liver tissue obtained from the mice with cancer cachexia receiving saline showed hepatocyte necrosis, liver cell cord derangement and hydropic or fatty degeneration of liver cells (Fig. 1B), which were relieved 
Table I. L-carnitine decreases serum levels of MDA, SOD and GSH-Px oxidative-stress markers.

\begin{tabular}{|c|c|c|c|c|}
\hline Marker & Normal control & Vehicle control & L-carnitine & L-carnitine + etomoxir \\
\hline MDA (nmol/ml) & $7.60 \pm 1.01$ & $10.35 \pm 0.40^{\mathrm{a}}$ & $9.37 \pm 0.65^{b}$ & $10.2 \pm 0.33^{c}$ \\
\hline $\mathrm{SOD}(\mathrm{U} / \mathrm{ml})$ & $90.08 \pm 1.67$ & $55.81 \pm 8.64^{\mathrm{a}}$ & $75.77 \pm 3.54^{\mathrm{b}}$ & $56.4 \pm 7.51^{\mathrm{d}}$ \\
\hline GSH-Px (U/ml) & $222.43 \pm 11.7$ & $180.6 \pm 6.22^{\mathrm{a}}$ & $204.03 \pm 6.06^{\mathrm{e}}$ & $179.39 \pm 11.77^{\mathrm{d}}$ \\
\hline
\end{tabular}

Data are presented as the mean \pm standard deviation. ${ }^{\mathrm{a}} \mathrm{P}<0.01$, vs. normal control; ${ }^{\mathrm{b}} \mathrm{P}<0.05$ vs. vehicle control; ${ }^{\mathrm{c}} \mathrm{P}<0.05$ and ${ }^{\mathrm{d}} \mathrm{P}<0.01, \mathrm{vs}$. L-carnitine; ${ }^{\mathrm{P}}<0.01$ vs. vehicle control. MDA, malondialdehyde; SOD, superoxide dismutase; GSH-Px, glutathione peroxidase.
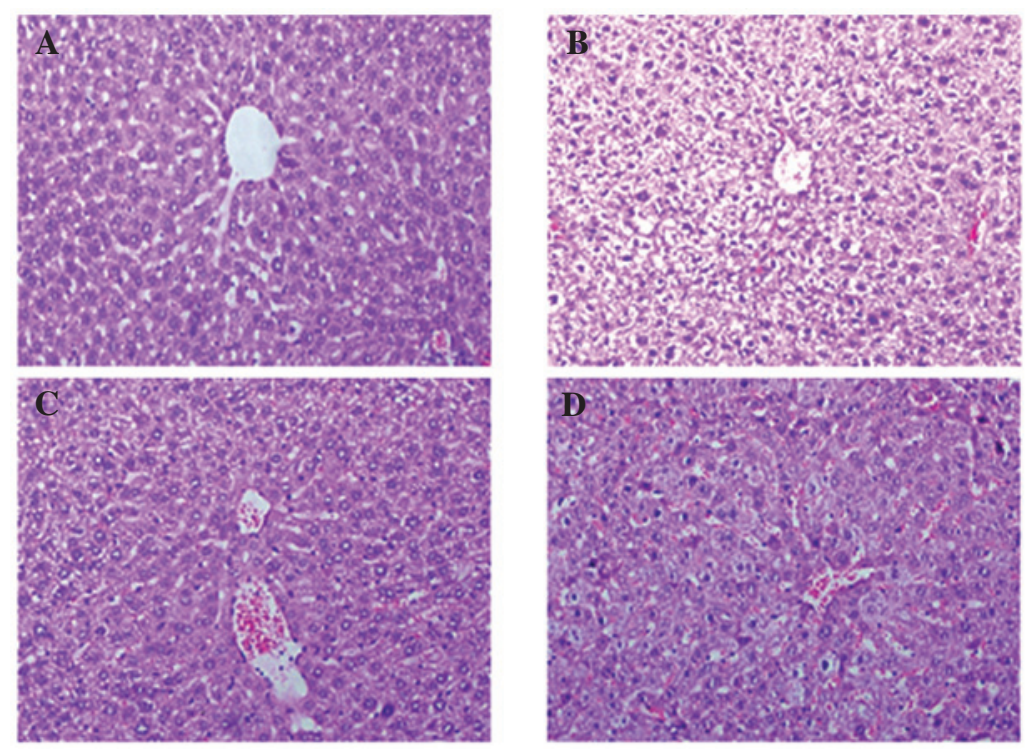

Figure 1. L-carnitine ameliorates the liver inflammatory response in cachectic mice. (A) Normal control; in healthy mice, liver tissue organization was normal and liver cell cords were well-arranged without lipid droplets. (B) Cachectic mice administered with saline; hepatocyte necrosis, liver cell-cord derangement and hydropic or fatty degeneration of liver cells were observed. (C) Cachectic mice administered with oral L-carnitine (9 mg/kg daily). The liver cell cord-derangement was partly restored, and hepatocyte necrosis reduced compared with that in panel B. (D) Cachectic mice administered with L-carnitine $(9 \mathrm{mg} / \mathrm{kg}$ daily) + etomoxir (20 mg/kg daily). Compared to panel $\mathrm{C}$, the liver cell-cord arrangement was less uniform and an increased amount of liver-cell necrosis was observed. Sections were stained using hematoxylin and eosin for examination of the inflammatory response (magnification, x100).

markedly by L-carnitine (Fig. 1C). The effects of L-carnitine on the liver inflammatory response were reversed notably by etomoxir, the inhibitor of CPT I (Fig. 1D).

Effects of L-carnitine on serum levels of MDA, SOD and $G S H$-Px. Compared with the healthy mice, there was a significant increase in the serum levels of MDA, and a significant decrease in the serum levels of SOD and GSH-Px in the mice with cachexia receiving saline. However, L-carnitine markedly increased the serum levels of SOD and GSH-Px, and significantly reduced the serum levels of MDA, compared with the mice with cachexia receiving saline, and these effects of L-carnitine were impaired markedly by treatment with etomoxir (Table I).

Effects of L-carnitine on the protein expression levels of PPAR- $\alpha / P P A R-\gamma$ in the liver of mice with cachexia. In the normal control mice, the expression levels of PPAR $\alpha$ and PPAR $\gamma$ were detected at basal level, which were decreased markedly at the protein level in the mice with cachexia receiving saline. However, these changes were reversed following treatment of animals with L-carnitine alone. This reversal effect of
L-carnitine on the decreased expression levels of PPAR- $\alpha$ and PPAR $\gamma$ in the mice with cachexia receiving saline was almost eradicated following etomoxir treatment (Fig. 2A and B).

$L$-carnitine decreases the expression of $N F-\kappa B$ p65 in the $P B M C$ s of mice with cancer cachexia in a PPAR $\gamma$-dependent manner. Compared with the normal control mice, the mRNA and protein expression levels of NF- $\mathrm{NB}$ p65 in the PBMCs were markedly elevated in the mice with cancer cachexia receiving saline. However, the increased expression of $\mathrm{NF}-\kappa \mathrm{B}$ p65 in the mice of the vehicle control group was decreased significantly by L-carnitine or pioglitazone (a specific agonist of PPAR $\gamma$ ). The effects of L-carnitine on NF- $\kappa$ B p65 at the mRNA (Fig. 3A) and protein (Fig. 3B) levels were significantly weakened by GW9662, a selective inhibitor of PPAR- $\gamma$.

L-carnitine decreases the expression of Cox-2 in the livers of mice with cachexia, partly by suppressing $N F-\kappa B$ signaling. NF- $\mathrm{B}$ p65 (Fig. 4A) and Cox-2 (Fig. 4B) were expressed at basal levels in the livers of the normal control mice, and were elevated in the livers of the mice with cachexia. L-carnitine 

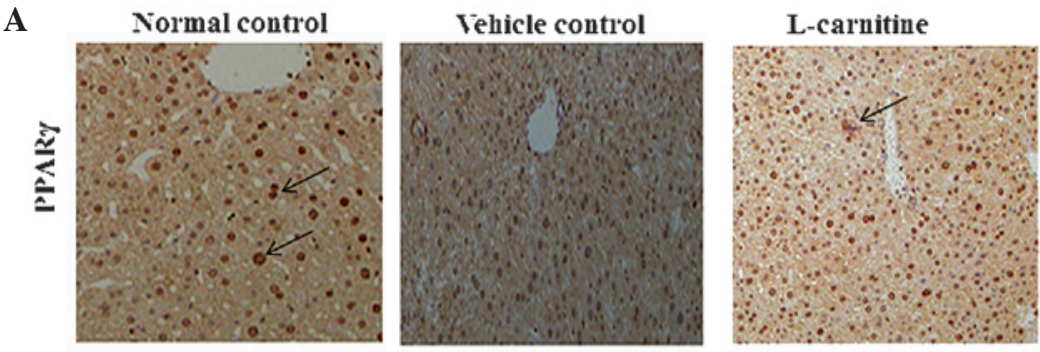

L-carnitine plus etomoxir
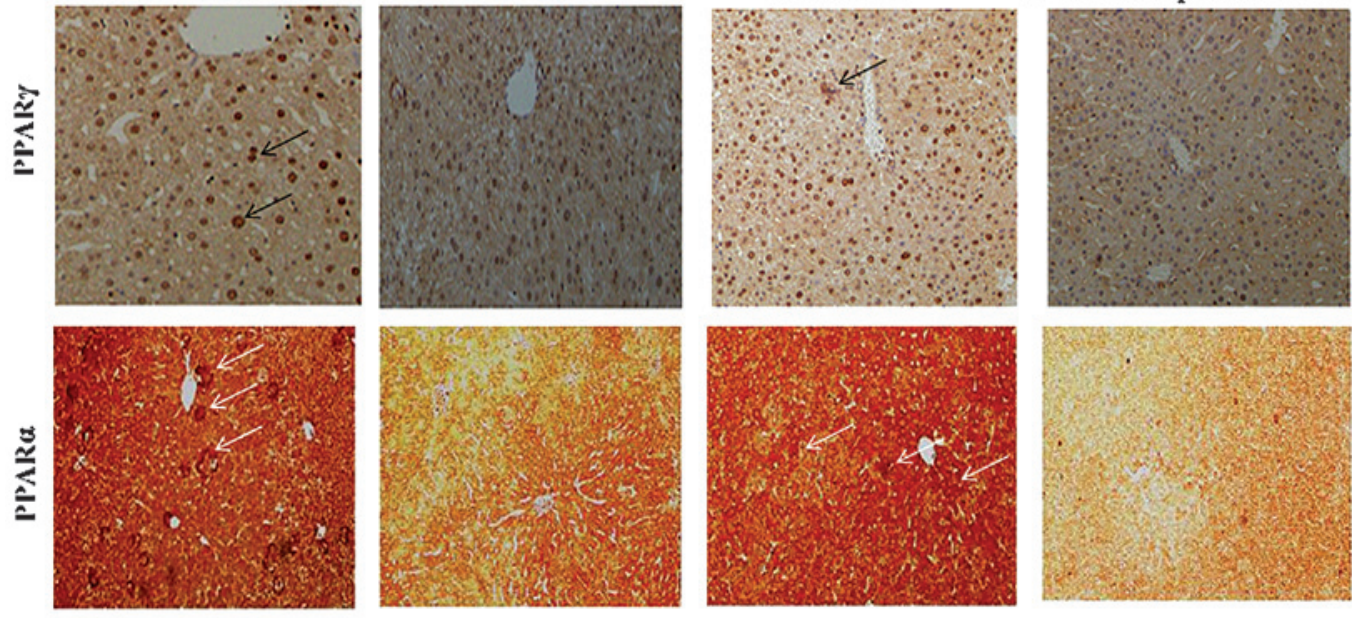

B

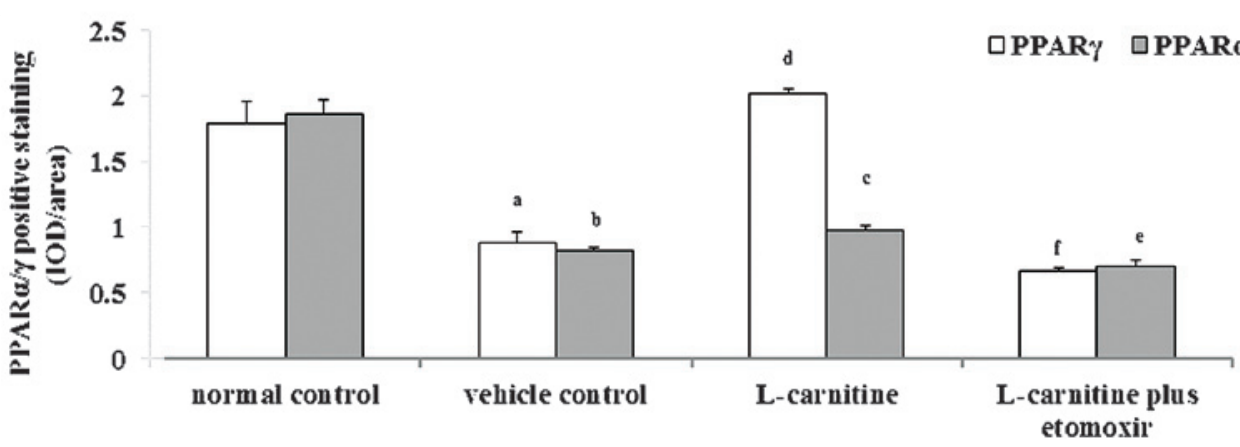

Figure 2. Effects of L-carnitine on protein expression levels of PPAR $\alpha$ and PPAR $\gamma$ in the liver of cachectic mice. (A) Cancer cachectic mice were administered with saline (vehicle control), L-carnitine ( $9 \mathrm{mg} / \mathrm{kg}$ per day), and CPT I inhibitor etomoxir ( $20 \mathrm{mg} / \mathrm{kg}$ per day) + L-carnitine for 8 days (n=6 in each group), following which then the protein levels of PPAR $\alpha$ and PPAR $\gamma$ in the liver were assayed using immunohistochemistry. Healthy untreated mice were used as normal controls $(n=6)$. The positive staining for PPAR $\alpha$ and PPAR $\gamma$ is indicated by the white and black arrows, respectively (magnification, $\mathrm{x} 100)$. (B) The relative expression levels of PPAR $\alpha$ and PPAR $\gamma$ were semi-quantitated as the IOD/area. Data are expressed as the mean \pm standard deviation. ${ }^{a} \mathrm{P}<0.05$ and ${ }^{b} \mathrm{P}<0.01$, vs. normal control; ${ }^{\mathrm{C}} \mathrm{P}<0.05$ and ${ }^{\mathrm{d}} \mathrm{P}<0.01$, vs. vehicle control; ${ }^{\mathrm{e}} \mathrm{P}<0.05$ and ${ }^{\mathrm{f}} \mathrm{P}<0.01$, vs. L-carnitine. PPAR, peroxisome proliferator-activated receptor; CPT I, carnitine palmitoyltransferase I; IOD, integrated optical density.

A

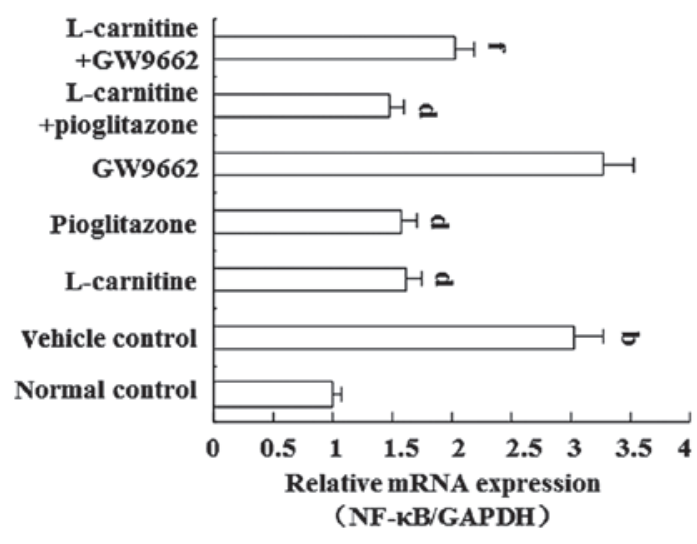

B

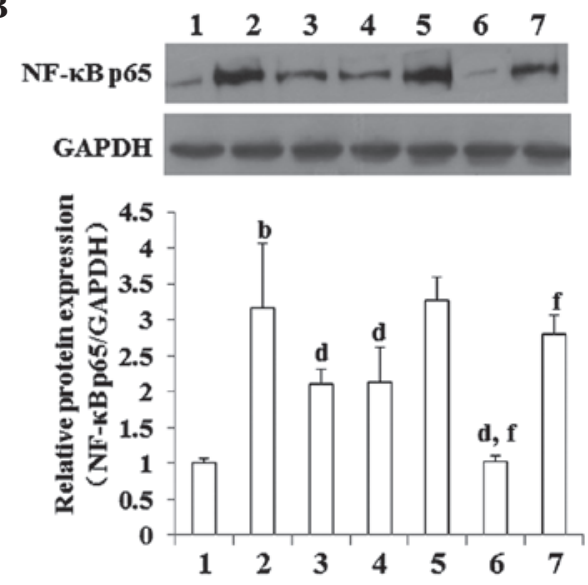

Figure 3. L-carnitine decreases the serum expression levels of NF- $\kappa \mathrm{B}$ p65 in cachectic mice. Cancer cachectic mice were administered saline (vehicle control; Lane 2), oral L-carnitine (9 mg/kg per day; Lane 3), oral pioglitazone hydrochloride (10 mg/kg daily; Lane 4), intraperitoneal GW9662 (1 mg/kg daily; Lane 5), oral L-carnitine \pm pioglitazone hydrochloride (Lane 6), and L-carnitine + GW9662 for 8 days (n=6 in each group; Lane 7), following which the serum concentration of NF- $\kappa$ B p65 were determined at the (A) mRNA and (B) protein levels in peripheral blood mononuclear cells using reverse transcription-quantitative polymerase chain reaction and western blot analysis, respectively. Healthy untreated mice were used as normal controls (n=6; Lane 1). Data are expressed as the mean \pm standard deviation. ${ }^{\mathrm{b}} \mathrm{P}<0.01$, vs. normal control; ${ }^{\mathrm{d}} \mathrm{P}<0.01$, vs. vehicle control; ${ }^{\mathrm{f}} \mathrm{P}<0.01$, vs. L-carnitine. NF- $\kappa \mathrm{B}$, nuclear factor- $\kappa \mathrm{B}$.

decreased the elevated expression levels of NF- $\mathrm{KB}$ p65 and Cox-2 in the livers of the mice with cachexia. This effect of L-carnitine was reversed by GW9662, a selective inhibitor of
PPAR $\gamma$. The inhibitory effect of GW9662 on L-carnitine on Cox-2 was impaired by PDTC, a selective inhibitor of NF- $\kappa B$ signaling. 
Table II. L-carnitine decreases serum levels of pro-inflammatory agents in cancer cachectic mice.

\begin{tabular}{lcrrrrr}
\hline $\begin{array}{l}\text { Inflammatory } \\
\text { agent }(\mathrm{pg} / \mathrm{ml})\end{array}$ & $\begin{array}{c}\text { Normal } \\
\text { control }\end{array}$ & \multicolumn{1}{c}{$\begin{array}{l}\text { Vehicle } \\
\text { control }\end{array}$} & L-carnitine & GW9662 & $\begin{array}{c}\text { L-carnitine+ } \\
\text { GW9662 }\end{array}$ & $\begin{array}{c}\text { L-carnitine+ } \\
\text { GW9662+PDTC }\end{array}$ \\
\hline PGE2 & $40.01 \pm 1.43$ & $122.83 \pm 4.13^{\mathrm{a}}$ & $108.00 \pm 1.08^{\mathrm{b}}$ & $131.82 \pm 4.84$ & $121.17 \pm 4.35^{\mathrm{c}}$ & $103.01 \pm 6.62^{\mathrm{e}}$ \\
CRP & $7.19 \pm 0.57$ & $16.98 \pm 1.48^{\mathrm{a}}$ & $10.52 \pm 1.01^{\mathrm{b}}$ & $17.71 \pm 0.97$ & $15.64 \pm 0.83^{\mathrm{d}}$ & $9.67 \pm 0.53^{\mathrm{f}}$ \\
IL-6 & $2.69 \pm 0.31$ & $28.11 \pm 5.20^{\mathrm{a}}$ & $16.44 \pm 2.58^{\mathrm{b}}$ & $28.22 \pm 5.56$ & $28.81 \pm 3.85^{\mathrm{d}}$ & $17.53 \pm 2.46^{\mathrm{f}}$ \\
TNF- $\alpha$ & $1.68 \pm 0.38$ & $35.25 \pm 3.00^{\mathrm{a}}$ & $19.98 \pm 2.78^{\mathrm{b}}$ & $32.22 \pm 2.89$ & $29.48 \pm 3.68^{\mathrm{d}}$ & $22.81 \pm 1.76^{\mathrm{e}}$ \\
\hline
\end{tabular}

Data are presented as the mean \pm standard deviation. ${ }^{\mathrm{a}} \mathrm{P}<0.01$, vs. Normal control; ${ }^{\mathrm{b}} \mathrm{P}<0.01$ vs. Vehicle control; ${ }^{\mathrm{c}} \mathrm{P}<0.05$ and ${ }^{\mathrm{d}} \mathrm{P}<0.01, \mathrm{vs}$. L-carnitine; ${ }^{~} \mathrm{P}<0.05$ and ${ }^{\mathrm{f}} \mathrm{P}<0.01$, vs. L-carnitine+GW9662. PGE2, prostaglandin E2; CRP, C-reactive protein; IL-16, interleukin-6; TNF- $\alpha$, tumor necrosis factor- $\alpha$. PDTC, pyrrolidine dithiocarbamate.

A
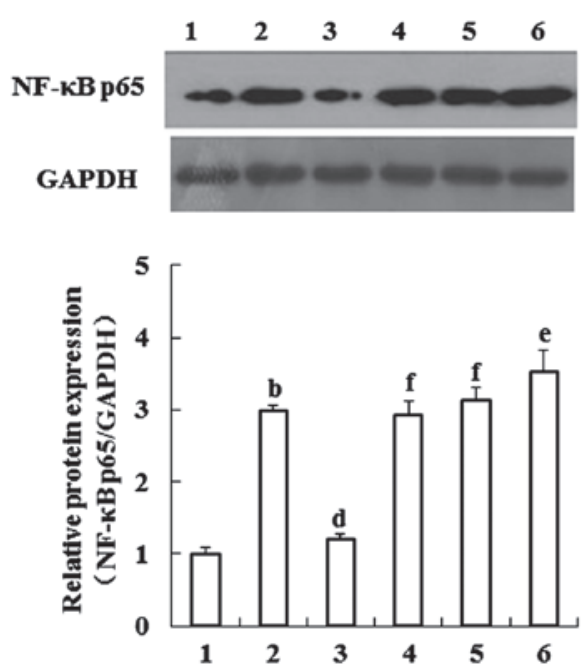

B
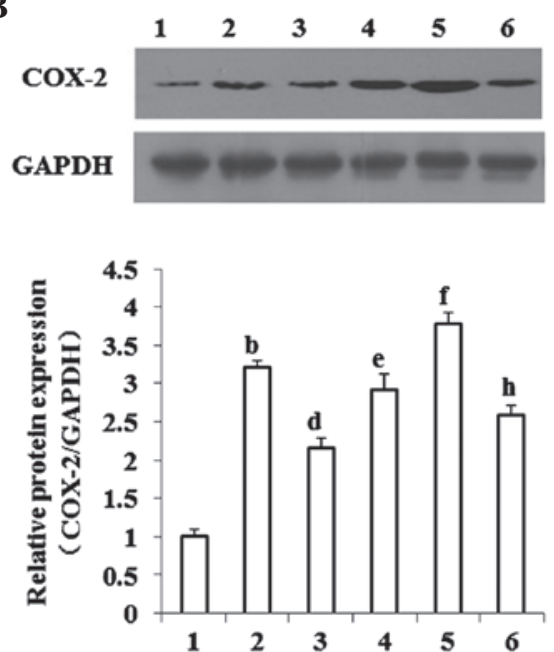

Figure 4. L-carnitine decreases the liver expression levels of Cox-2 in cachectic mice partly by suppressing NF- $\kappa \mathrm{B}$ signaling. Cancer cachectic mice received saline (vehicle control; Lane 2), oral L-carnitine (9 mg/kg per day; Lane 3), intraperitoneal GW9662 (1 mg/kg daily; Lane 4), L-carnitine + GW9662 (Lane 5) and L-carnitine+GW9662+PDTC (120 mg/kg per day; Lane 6) for 8 days ( $\mathrm{n}=6$ in each group). Expression levels of (A) NF-кB p65 and (B) Cox-1 were examined in the liver using western blot analysis. Healthy untreated mice were used as normal controls $(n=6)$. Data are expressed as the mean \pm standard deviation. ${ }^{b} \mathrm{P}<0.01$, vs. normal control; ${ }^{\mathrm{d}} \mathrm{P}<0.01$, vs. vehicle control; ${ }^{\mathrm{e}} \mathrm{P}<0.05$ and ${ }^{\mathrm{f}} \mathrm{P}<0.01$, vs. L-carnitine; ${ }^{\mathrm{h}} \mathrm{P}<0.01$, vs. L-carnitine $+\mathrm{GW} 9662$. Cox-2, cyclooxygenase-2; $\mathrm{NF}-\kappa \mathrm{B}$, nuclear factor- $\kappa \mathrm{B}$.

L-carnitine decreases the serum levels of PGE2, CRP, TNF- $\alpha$ and IL-6 pro-inflammatory markers in mice with cachexia, partly by suppressing PPAR $\gamma-N F-\kappa B$ signaling. Compared with the healthy mice, there was a significant increase in the serum levels of PGE2, CRP, TNF- $\alpha$ and IL- 6 in the mice with cachexia receiving saline. The serum concentrations of these markers were decreased markedly by L-carnitine. This effect of L-carnitine was impaired by GW9662, and PDTC reversed the effect of GW9662 on the inhibition serum pro-inflammatory markers by L-carnitine (Table II).

\section{Discussion}

Cancer cachexia is a wasting syndrome, which is characterized by systemic inflammation, body weight loss, atrophy of white adipose tissue and skeletal muscle, all of which are often correlated with high mortality rates and poor quality of life in patients with cancer (2). Liver lipid metabolism disorders contribute to cancer cachexia symptoms through inducing the pro-inflammatory response in the liver to aggravate systemic inflammation $(8,25)$. A previous study (21) demonstrated that L-carnitine, a key regulator of lipid metabolism, induces the recovery of lipid metabolism disorders in the liver, and decrease circulating pro-inflammatory cytokines to improve the symptoms of cachexia in association with regulating the expression and activity of CPT. This suggests that CPT is pivotal in the regulation of L-carnitine in the liver inflammatory response. The results of the present study demonstrated that L-carnitine attenuated the liver inflammatory response and oxidative stress via CPT I-dependent PPAR $\gamma-\mathrm{NF}-\kappa \mathrm{B}$ signaling.

The liver is the major site of lipid metabolism and a predominant source of circulating pro-inflammatory factors in cancer cachexia $(12,16)$. Patients with hepatocellular carcinoma which progresses to cancer cachexia often exhibit accompanied chronic liver inflammation, which is one of the major factors leading to poor prognosis (26). Our previous study showed that L-carnitine ameliorates the symptoms of cancer cachexia (3). In the present study, it was found that L-carnitine ameliorated the liver inflammatory response by relieving hepatocyte necrosis, liver cell cord derangement and hydropic or fatty degeneration of liver cells, suggesting 
that L-carnitine ameliorated cancer cachexia by inducing the recovery from liver inflammation. In addition, etomoxir, as an inhibitor of CPT I almost eradicated the effect of L-carnitine on liver inflammation, suggesting that CPT I was a mediator in the improvement of liver inflammation by L-carnitine.

The $\beta$-oxidation of fatty acids in the mitochondria is disrupted in the liver in cancer cachexia, resulting in oxidative stress (27), which is supported by the results of the present study that the serum levels of oxidative stress markers were increased in the mice with cancer cachexia. The dysfunction of mitochondria in $\beta$-oxidation finally induces a pro-inflammatory response. In the present study, the results showed that L-carnitine decreased the elevated levels of oxidative stress markers, suggesting that L-carnitine relieved the liver inflammatory response by inhibiting oxidative stress. Our previous study demonstrated that the activity of CPT I, a key mediator in the $\beta$-oxidation of fatty acids, is decreased in the mitochondria of the livers of mice with cachexia liver, and is increased by L-carnitine (3). In the present study, it was demonstrated that etomoxir, as an inhibitor of CPT I, reversed the amelioratory effect of L-carnitine on oxidative stress. These results suggested that L-carnitine inhibited oxidative stress and improved liver inflammation in a CPT I-dependent manner.

PPARs are transcription factors belonging to a superfamily of nuclear receptors, and three isoforms $(\alpha, \delta$ and $\gamma$ ) have been described, in which PPAR $\alpha$ and $\gamma$ are known to regulate lipid metabolism and oxidative stress $(28,29)$. Furthermore, PPAR $\alpha$ and $\gamma$ have been previously demonstrated to exert an inhibitory effect on tumor growth, muscle atrophy, and pro-inflammatory cytokine secretion and signaling in cancer cachexia (30-33). In the present study, the protein expression levels of PPAR $\alpha$ and $\gamma$ in the liver were decreased in the mice with cancer cachexia, which was accompanied by a notable liver inflammatory response. These changes were restored by L-carnitine, suggesting that L-carnitine improved the liver inflammatory response by regulating the expression levels of PPAR $\alpha$ and/or PPAR $\gamma$.

Notably, it has been demonstrated that PPAR $\alpha$ and PPAR $\gamma$ coactivators induce the expression of CPT I through different regions of the CPT-1A gene (21). In the present study, the promotion by L-carnitine on the expression levels of PPAR $\alpha$ and $\gamma$ were reversed by etomoxir, an inhibitor of CPT, suggesting that L-carnitine regulated the expression of PPAR in a CPT I-dependent manner, and that CPT I may have an indirect effect on regulating the expression of PPAR. Although the present study was unable to provide direct evidence that CPT I induces the expression of PPAR, the results indicated that L-carnitine ameliorated the liver inflammatory response by regulating CPT I-dependent PPAR signaling.

Of note, the present study demonstrated that the increase in the expression of PPAR $\gamma$ in the liver induced by L-carnitine was more significant, compared with that of PPAR $\alpha$, suggesting that the amelioration effects of L-carnitine on the liver inflammatory response may be dependent more on PPAR $\gamma$ and less on PPAR $\alpha$ signaling. These results are consistent with those of a previous study in a cyclophosphamide-induced hepatotoxic model, which reported that PPAR $\gamma$ signaling, but not PPAR $\alpha$ signaling, mediated antioxidant and anti-inflammatory effects in the liver (19).
$\mathrm{NF}-\kappa \mathrm{B}$ is known to regulate liver inflammation and oxidative stress (34). A previous study (35) demonstrated that the elevation in the expression levels of $\mathrm{NF}-\kappa \mathrm{B}$ p 65 contributes substantially to the progression of cancer cachexia, suggesting that NF- $\mathrm{NB}$ signaling is essential in cancer cachexia, which is also supported by the findings of the present study, in which the expression of $\mathrm{NF}-\kappa \mathrm{B}$ p 65 was increased in the PBMCs at the mRNA and protein levels. Studies $(36,37)$ have also demonstrated that NF- $\kappa$ B is a downstream mediator of PPAR $\alpha$ and PPAR $\gamma$ signaling in the liver, which is supported by our findings that increased expression levels of NF- $\mathrm{B}$ p 65 are inhibited by pioglitazone, a specific agonist of PPAR $\gamma$. Notably, treatment of mice in the present study with L-carnitine alone decreased the expression of $\mathrm{NF}-\kappa \mathrm{B}$ p 65 in cancer cachexia, and this effect of L-carnitine was reversed by GW9662, a selective inhibitor of PPAR- $\gamma$, suggesting that L-carnitine inhibited the expression of NF- $\mathrm{B}$ p 65 in a PPAR $\gamma$-dependent manner. However, the exact role of PPAR $\alpha$ in the regulation of L-carnitine on the expression of $\mathrm{NF}-\kappa \mathrm{B}$ p 65 requires further investigated in the future.

The Cox-2/PGE2 pathway is important in regulating oxidative stress and inflammation in the liver (38). Celecoxib, a specific inhibitor of Cox-2, downregulates serum inflammatory cytokines in patients with cancer cachexia (10). In the present study, the increased levels of Cox-2 in the liver of mice with cancer cachexia were decreased by L-carnitine, and this effect was reversed by treatment with GW9662. This effect of GW9662 on L-carnitine was restored by PDTC, a specific inhibitor of $\mathrm{NF}-\kappa \mathrm{B}$ signaling. These results suggested that L-carnitine decreased the expression of Cox-2 in the liver by PPAR $\gamma$-dependent NF- $\kappa$ B signaling.

Certain pro-inflammatory markers, including CRP, PGE2, IL- 6 and TNF- $\alpha$, are well known to promote systemic inflammation, thus aggravating the progression of cancer cachexia (39). In particular, CRP may induce IL-6 secretion, which is known to have a causative effect in cancer cachexia $(40,41)$. In the present study, it was found that the elevation of the above-mentioned pro-inflammatory markers were decreased by L-carnitine, and this inhibitory effect of L-carnitine was reversed by GW9662, suggesting that PPAR $\gamma$-dependent NF- $\kappa$ B signaling is pivotal in the inflammatory response in cancer cachexia.

One of the limitations of the present study was that the role of PPAR $\alpha$ in the regulation of liver inflammation by L-carnitine was not investigated, although a previous study demonstrated that it is PPAR $\gamma$, rather than PPAR $\alpha$, which exerts antioxidant and anti-inflammatory effects in the liver (19). However, other studies have demonstrated that PPAR $\alpha$ also exerts anti-inflammatory effects in the liver following ischemia-reperfusion injury (37), and is a therapeutic target in chronic obstructive pulmonary disease-induced cachexia, owing to its anti-inflammatory effect (42). This discrepancy may be explained by the different animal models used in these investigations. Therefore, the role of PPAR $\alpha$ in the amelioration of the liver inflammatory response by L-carnitine in cancer cachexia requires further investigation.

In conclusion, the present study demonstrated that L-carnitine ameliorated liver inflammation and serum pro-inflammatory markers in cancer cachexia via I-dependent PPAR $\gamma$ signaling, including the downstream molecules of 
$\mathrm{NF}-\kappa \mathrm{B}$ p65 and Cox-2. These results suggest that L-carnitine may be a candidate for the amelioration of systemic inflammation in cancer cachexia.

\section{Acknowledgements}

This study was supported by the Foundation of the Science and Technology Committee of Shanghai Zhabei District of China (grant no. 2012ZD04).

\section{References}

1. Trutschnigg B, Kilgour RD, Morais JA, Lucar E, Hornby L, Molla $\mathrm{H}$ and Vigano A: Metabolic, nutritional and inflammatory characteristics in elderly women with advanced cancer. J Geriatr Oncol 4: 183-189, 2013.

2. Richards $\mathrm{CH}$, Roxburgh CS, MacMillan MT, Isswiasi S, Robertson EG, Guthrie GK, Horgan PG and McMillan DC: The relationships between body composition and the systemic inflammatory response in patients with primary operable colorectal cancer. PLoS One 7: e41883, 2012.

3. Liu S, Wu HJ, Zhang ZQ, Chen Q, Liu B, Wu JP and Zhu L: L-carnitine ameliorates cancer cachexia in mice by regulating the expression and activity of carnitine palmityl transferase. Cancer Biol Ther 12: 125-130, 2011.

4. Jiang Y, Guo C, Zhang D, Zhang J, Wang X and Geng C: The altered tight junctions: An important gateway of bacterial translocation in cachexia patients with advanced gastric cancer. J Interferon Cytokine Res 34: 518-525, 2014.

5. Wang LH, Yang XY, Mihalic K, Xiao W, Li D and Farrar WL: Activation of estrogen receptor blocks interleukin-6-inducible cell growth of human multiple myeloma involving molecular cross-talk between estrogen receptor and STAT3 mediated by co-regulator PIAS3. J Biol Chem 276: 31839-31844, 2001.

6. Bonetto A, Aydogdu T, Kunzevitzky N, Guttridge DC, Khuri S, Koniaris LG and Zimmers TA: STAT3 activation in skeletal muscle links muscle wasting and the acute phase response in cancer cachexia. PLoS One 6: e22538, 2011.

7. Martignoni ME, Dimitriu C, Bachmann J, Krakowski-Rosen H, Ketterer K, Kinscherf R and Friess H: Liver macrophages contribute to pancreatic cancer-related cachexia. Oncol Rep 21: 363-369, 2009

8. Watchorn TM, Dowidar N, Dejong CH, Waddell ID, Garden OJ and Ross JA: The cachectic mediator proteolysis inducing factor activates NF-kappaB and STAT3 in human Kupffer cells and monocytes. Int J Oncol 27: 1105-1111, 2005.

9. Wang W, Andersson M,Lõnnroth C, Svanberg E and Lundholm K: Prostaglandin E and prostacyclin receptor expression in tumor and host tissues from MCG 101-bearing mice: A model with prostanoid-related cachexia. Int J Cancer 115: 582-590, 2005

10. Mantovani G, Macciò A, Madeddu C, Serpe R, Antoni G Massa E, Dessì $\mathrm{M}$ and Panzone F: Phase II nonrandomized study of the efficacy and safety of COX-2 inhibitor celecoxib on patients with cancer cachexia. J Mol Med (Berl) 88: 85-92, 2010.

11. Sue YM, Chou HC, Chang CC, Yang NJ, Chou Y and Juan SH: L-carnitine protects against carboplatin-mediated renal injury: AMPK- and PPAR $\alpha$-dependent inactivation of NFAT3. PLoS One 9: e104079, 2014.

12. Ishikawa H, Takaki A, Tsuzaki R, Yasunaka T, Koike K, Shimomura Y, Seki H, Matsushita H, Miyake Y, Ikeda F, et al: L-carnitine prevents progression of non-alcoholic steatohepatitis in a mouse model with upregulation of mitochondrial pathway. PLoS One 9: e100627, 2014.

13. Demiroren K, Dogan Y, Kocamaz H, Ozercan IH, Ilhan S, Ustundag B and Bahcecioglu IH: Protective effects of $\mathrm{L}$-carnitine, $\mathrm{N}$-acetylcysteine and genistein in an experimental model of liver fibrosis. Clin Res Hepatol Gastroenterol 38: 63-72, 2014.

14. Vinci E, Rampello E, Zanoli L, Oreste G, Pistone G and Malaguarnera M: Serum carnitine levels in patients with tumoral cachexia. Eur J Intern Med 16: 419-423, 2005.

15. Breitkreutz R, Babylon A, Hack V, Schuster K, Tokus M, Böhles H, Hagmüller E, Edler L, Holm E and Dröge W: Effect of carnitine on muscular glutamate uptake and intramuscular glutathione in malignant diseases. Br J Cancer 82: 399-403, 2000
16. Khan SA, Ali A, Khan SA, Zahran SA, Damanhouri G, Azhar E and Qadri I: Unraveling the complex relationship triad between lipids, obesity and inflammation. Mediators Inflamm 2014: 502749, 2014

17. Silverio R, Laviano A, Rossi Fanelli F and Seelaender M: L-Carnitine induces recovery of liver lipid metabolism in cancer cachexia. Amino Acids 42: 1783-1792, 2012.

18. Zambrano S, Blanca AJ, Ruiz-Armenta MV, Miguel-Carrasco JL, Arévalo M, Vázquez MJ, Mate A and Vázquez CM: L-Carnitine protects against arterial hypertension-related cardiac fibrosis through modulation of PPAR- $\gamma$ expression. Biochem Pharmacol 85: 937-944, 2013.

19. El-Sheikh AA and Rifaai RA: Peroxisome proliferator activator receptor (PPAR)- $\gamma$ ligand, but Not PPAR- $\alpha$, ameliorates cyclophosphamide-induced oxidative stress and inflammation in rat liver. PPAR Res 2014: 626319, 2014.

20. Chen K, Li J, Wang J, Xia Y, Dai W, Wang F, Shen M, Cheng P, Zhang Y, Wang C, et al: 15-Deoxy- $\gamma$ 12,14-prostaglandin J2 reduces liver impairment in a model of ConA-induced acute hepatic inflammation by activation of PPAR $\gamma$ and Reduction in NF- $\kappa$ B Activity. PPAR Res 2014: 215631, 2014

21. Song S, Attia RR, Connaughton S, Niesen MI, Ness GC, Elam MB, Hori RT, Cook GA and Park EA: Peroxisome proliferator activated receptor alpha (PPARalpha) and PPARgamma coactivator (PGC-1alpha) induce carnitine palmitoyltransferase IA (CPT-1A) via independent gene elements. Mol Cell Endocrinol 325: 54-63, 2010.

22. Kashinakunti SV, Kollur P, Kallaganada GS, Rangappa M and Ingin JB: Comparative study of serum MDA and vitamin $\mathrm{C}$ levels in non-smokers, chronic smokers and chronic smokers with acute myocardial infarction in men. J Res Med Sci 16: 993-998, 2011.

23. Hübscher SG: Histological assessment of non-alcoholic fatty liver disease. Histopathology 49: 450-465, 2006.

24. Jia XL, Li SY, Dang SS, Cheng YA, Zhang X, Wang WJ, Hughes CE and Caterson B: Increased expression of chondroitin sulphate proteoglycans in rat hepatocellular carcinoma tissues. World J Gastroenterol 18: 3962-3976, 2012.

25. Tisdale MJ: Mechanisms of cancer cachexia. Physiol Rev 89: 381-410, 2009.

26. Luna G, Florence L and Johansen K: Hepatocellular carcinoma. A 5 year institutional experience. Am J Surg 149: 591-594, 1985.

27. Barreiro E, de la Puente B, Busquets S, López-Soriano FJ, Gea J and Argiles JM: Both oxidative and nitrosative stress are associated with muscle wasting in tumour-bearing rats. FEBS Lett 579: 1646-1652, 2005.

28. Zeng T, Zhang CL, Song FY, Zhao XL and Xie KQ: CMZ reversed chronic ethanol-induced disturbance of PPAR- $\alpha$ possibly by suppressing oxidative stress and PGC-1 $\alpha$ acetylation and activating the MAPK and GSK3 $\beta$ pathway. PLoS One 9: e98658, 2014

29. Al Rouq F and El Eter E: PPAR- $\gamma$ activator induces neuroprotection in hypercholesterolemic rats subjected to global cerebral ischemia/reperfusion injury: In vivo and in vitro inhibition of oxidative stress. Exp Gerontol 51: 1-7, 2014.

30. Moore-Carrasco R, Figueras M, Ametller E, López-Soriano FJ, Argilés JM and Busquets S: Effects of the PPARgamma agonist GW1929 on muscle wasting in tumour-bearing mice. Oncol Rep 19: 253-256, 2008.

31. Puigserver P, Rhee J, Lin J, Wu Z, Yoon JC, Zhang CY, Krauss S, Mootha VK, Lowell BB and Spiegelman BM: Cytokine stimulation of energy expenditure through p38 MAP kinase activation of PPARgamma coactivator-1. Mol Cell 8: 971-982, 2001.

32. Asp Ml, Tian M, Kliewer KL and Belury MA: Rosiglitazone delayed weight loss and anorexia while attenuating adipose depletion in mice with cancer cachexia. Cancer Biol Ther 12: 957-965, 2011.

33. Huang J, Das SK, Jha P, Al Zoughbi W, Schauer S, Claudel T, Sexl V, Vesely P, Birner-Gruenberger R, Kratky D, et al: The PPAR $\alpha$ agonist fenofibrate suppresses B-cell lymphoma in mice by modulating lipid metabolism. Biochim Biophys Acta 1831: $1555-1565,2013$.

34. Yuan K, Huang C, Fox J, Gaid M, Weaver A, Li G, Singh BB, Gao $\mathrm{H}$ and $\mathrm{Wu} \mathrm{M}$ : Elevated inflammatory response in caveolin-1-deficient mice with Pseudomonas aeruginosa infection is mediated by STAT3 protein and nuclear factor kappaB (NF-kappaB). J Biol Chem 286: 21814-21825, 2011.

35. Zhou W, Jiang ZW, Tian J, Jiang J, Li N and Li JS: Role of NF-kappaB and cytokine in experimental cancer cachexia. World J Gastroenterol 9: 1567-1570, 2003. 
36. Li CC, Yang HT, Hou YC, Chiu YS and Chiu WC: Dietary fish oil reduces systemic inflammation and ameliorates sepsis-induced liver injury by up-regulating the peroxisome proliferator-activated receptor gamma-mediated pathway in septic mice. J Nutr Biochem 25: 19-25, 2014.

37. Zuniga J, Cancino M, Medina F, Varela P, Vargas R, Tapia G, Videla LA and Fernández V: N-3 PUFA supplementation triggers PPAR- $\alpha$ activation and PPAR-alpha/NF- $\mathrm{B}$ interaction: Anti-inflammatory implications in liver ischemia-reperfusion injury. PLoS One 6: e28502, 2011.

38. Ozturk H, Gezici A and Ozturk H: The effect of celecoxib, a selective COX-2 inhibitor, on liver ischemia/reperfusion-induced oxidative stress in rats. Hepatol Res 34: 76-83, 2006.
39. Onesti JK and Guttridge DC: Inflammation based regulation of cancer cachexia. Biomed Res Int 2014: 168407, 2014.

40. Cossette E, Cloutier I, Tardif K, DonPierre G and Tanguay JF: Estradiol inhibits vascular endothelial cells pro-inflammatory activation induced by C-reactive protein. Mol Cell Biochem 373: 137-147, 2013.

41. White JP, Baltgalvis KA, Puppa MJ, Sato S, Baynes JW and Carson JA: Muscle oxidative capacity during IL-6-dependent cancer cachexia. Am J Physiol Regul Integr Comp Physiol 300: R201-R211, 2011.

42. Remels AH, Gosker HR, Langen RC and Schols AM: The mechanisms of cachexia underlying muscle dysfunction in COPD. J Appl Physiol (1985) 114: 1253-1262, 2013. 